\title{
ProceEdings From
}

SEMANTICS

AND

LINGUISTIC

THEORY

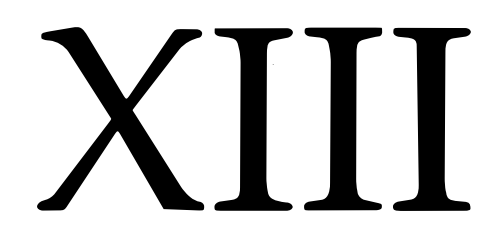

EDITED BY

Robert B. Young AND YuPING ZHOU

Cornell University

ITHACA 2003 
Klaus Abels

Who Gives a Damn about Minimizers in Questions?...

Nicholas Asher and Linton Wang

Ambiguity and Anaphora with Plurals in Discourse.

David Beaver and Cleo Condoravdi

A Uniform Analysis of Before and After

Richard Breheny

A Lexical Account of Implicit (Bound) Contextual Dependence

Edit Doron

Bare Singular Reference to Kinds

Jean Mark Gawron and Andrew Kehler

Respective Answers to Coordinated Questions.

Daniel Hardt

Sloppy Identity, Binding, and Centering.

Michela Ippolito

Quantification over Times in Subjunctive Conditionals.

Graham Katz

A Modal Account of the English Present Perfect Puzzle.

Ji-yung Kim

"Intermediate Scope" in (Mandarin) Chinese.

Manfred Krifka

Bare NPs: Kind-referring, Indefinites, Both, or Neither?

S.-Y. Kuroda

Milsark's Generalization and Categorical Judgments.

Dmitry Levinson

Probabilistic Model-theoretic Semantics for Want

Luisa Martí

Contextual Variables as Pronouns.

Uli Sauerland

A New Semantics for Number

Penka Stateva

Superlative More

Robert van Rooy and Marie Safárová

On Polar Questions.

Andrea Wilhelm

Quasi-Telic Perfective Aspect in Dëne Sụtiné (Chipewyan). 


\section{ACKNOWLEDGMENTS}

This proceedings contains papers from the thirteenth conference in Semantics and Linguistic Theory, May 9-11, 2003, at the University of Washington. We thank the conference organizers and the reviewers who rated and commented on the many abstracts submitted to the conference. Thanks especially to the authors, whose patient assistance has made the editorial task a pleasure. Unfortunately, the papers presented by Elena Guerzoni, Angelika Kratzer and William A. Ladusaw were not available for publication in this volume.

Finally, thanks to CLC publications, Sheila Haddad, Devon Strolovitch, Angie Tinti and the Field of Linguistics at Cornell University for making the publication possible.

Robert B. Young and Yuping Zhou

Editors

August 2003 